\title{
Toxicity of Neonicotinoids to Honey Bees and Detoxification Mechanism in Honey Bees
}

\author{
Vijayan Magesh, Zhen Zhu, Tianren Tang, Shaoe Chen, Li Li, Lidong Wang, \\ Kalidindi Krishna Varma and Yifan Wu* \\ Jiangsu Rotam Chemistry CO. Ltd, Road No.88, Rotam Road, ETDZ, Kunshan, Jiangsu, 215301, China.
}

\begin{abstract}
Agrochemicals are widely used in the present day agricultural practices and many non-targeted species like honey bees are affected by these agrochemicals and getting declined in the nature.To prevent this, detoxification mechanism needs to be studied and implemented in future aspects to protect the honey bees.Honeybee is a member of the genus Apis, involved in the production and storage of honey, construction of perennial, colonial nests from wax. Species of Apis mellifera pollinate a large variety of plants. Of all the honey bee species, only A.mellifera has been used extensively for commercial pollination of crops and other plants. Bees suffer serious effects from toxic chemicals in their environments. These include various synthetic chemicals, such as insecticides and fertilizers, as well as a variety of naturally occurring chemicals from plants. Insecticides are considered the major factors for the current decline in bee populations. However, detoxification mechanisms in healthy, unstressed honey bees are poorly characterized. A substance called p-coumaric acid specifically up-regulates all classes of detoxification genes as well as select antimicrobial peptide genes. This up-regulation has functional significancein that adding p-coumaric acid to a diet of sucrose increases midgut metabolism of coumaphos, a widely used in-hive acaricide, by $\sim 60 \%$. As a major component of pollen grains, $p$ coumaric acid is ubiquitous in the natural diet of honey bees and mayfunction as a nutraceutical regulating immune and detoxification processes. In less than 20 years, neonicotinoids have become the most widely used class of insecticides with a global market share of more than 25\%. These chemicals mimic the acetylcholine neurotransmitter and are highly neurotoxic to insects. At field realistic doses, neonicotinoids cause a wide range of adverse sublethal effects in honeybee andbumble bee colonies which affects colony performance through impairment of foraging success, brood and larval development, memory and learning, damage to the central nervous system, susceptibility to diseases, hive hygiene etc. The worldwide production of neonicotinoids is still mounting. Therefore a transition to pollinator-friendly alternatives to neonicotinoids is urgently needed for the sake of the sustainability of pollinator ecosystem services.
\end{abstract}

Keywords: Honey bees, Neonicotinoids, Imidacloprid, Apis mellifera, Insects.

\section{Introduction}

The introduction of the neonicotinoids, imidacloprid and thiacloprid, to the market in the early 1990s opened the neonicotinoid era of insect pest control (Tomizawa and casida 2011). Acting systemically, this new class of neurotoxic insecticides is taken up by plants, primarily through the roots, and getstranslocated to all parts ofthe plant through xylemic and phloemic transport (Bromilow et al., 1990). This systemic property combined withvery high toxicity to insects enabled formulating neonicotinoids for soiltreatment and seed coat with typical doses from 10 to $200 \mathrm{~g} /$ haenough to provide long lasting protectionof the whole plant from pest insects. Neonicotinoids interact with the nicotinic acetylcholine receptors (nAChRs) of the insect central nervous system. They act mainly agonistically on nAChRs on the postsynaptic membrane, mimicking acetylcholine, the natural neurotransmitter by binding with high affinity (Buckingham et al., 1997; Matsuda et al., 2001; Matsuda et al., 2005). This induces a neuronal hyper-excitation, which can lead to the insect's death within minutes (Belzunces et al., 2012; Tomizawaand casida, 2003; Palmer et al., 2013; Tomizawaand casida, 2005). In some cases though the chemical is directly not toxic to honeybees it may affect some of the behavioral symptoms like loss of memory, which leads to colony collapse disorder (CCD) which is one of the indirect effect to honeybees. Some of the major metabolites of neonicotinoids are equally neurotoxic, acting on the same receptors (Suchail et al., 2001;Suchail et al., 2004;Casida et al., 2010) thereby prolonging the effectiveness as systemic insecticide. The nAChR binding sites in the vertebrate nervous system are different from those in insects, and in general they have lower numbers of nicotinic receptors with high affinity to neonicotinoids, which are the reasons that neonicotinoids show selective toxicity for insects over vertebrates (Tomizawaand casida, 2005; Suchail et al., 2001, 2004; Casida et al., 2010; Liu et al., 2010). The main neonicotinoids presently on the market are imidacloprid, thiamethoxam, clothianidin, thiacloprid, dinotefuran, acetamiprid, nitenpyram and sulfoxaflor (Casida et al., 2010; Liu et al., 2008; Cutler et al., 2013). Ever since their launch, neonicotinoids have grown to become the most widely used and fastest growing class of insecticides with a 2010 global market 
share of $26 \%$ of the insecticide market (Casida et al., 2013) and imidacloprid is the second most widely used agrochemical in the world (Pollak, 2011).

The worldwide production of neonicotinoids still increasing (Shao et al., 2013) with a large-scale use in Europe and US started around 2004. Neonicotinoids are nowadays authorized in more than 120 countries for more than 1000 uses for the treatments of a wide range of plants including potato, rice, maize, sugar beets, cereals, oil rapeseed, sunflower, fruit, vegetables, soy, ornamental plants, tree nursery, seeds for export, and cotton. Neonicotinoids were assumed to be more efficient than the organophosphates and carbamates if they are replaced as seed treatment chemicals, they could be used in much lower quantities and they promised to be less polluting to the environment. It is however not the quantity that is relevant but the potency to cause harm, which results from toxicity, persistence and bioavailabilityto non-target species. Indeed, soon after the introduction of neonicotinoids, exposure to its residues in pollen, nectar, sowing dust, etc., of non-target pollinating insects became clear. This led to various harmful effects.

Bees near agricultural fields are exposed to a variety of pesticides via multiple routes at harmful levels throughout the foraging periods. Pesticides found include the neonicotinoids, clothianidin and thiomexotham, atrazine (an herbicide) and fungicides, including one known to synergize with neonicotinoids (propiconazole). Soils, pollen (bee collected and directly from plants), dandelions, dead and healthy bees, and planter waste products are all considered as potential exposure routes (Heather, 2012).

\section{Mode Of Action And Metabolism Of Neonicotinoid Insecticides}

In depth studies have been undertaken to fully understand the mechanisms involved in both neonicotinoid mode of action and target sites in addition to the detoxification mechanisms. Most of the studies in bee have been directed at the neonicotinoid imidacloprid, although few investigations have revealed the metabolism of acetamiprid, where, clothianidin is a metabolite of thiamethoxam in honeybees.

Generally in insects (including the honeybee), acetylcholine is the main neurotransmitter; it binds to nicotinic acetylcholine receptors (nAChR) mediating fast cholinergic synaptic transmission (Barbara et al., 2008; Thany et al., 2010). Honeybee sensory and motor functions are dependent on central and cholinergic pathways (Tomizawa and Yamamoto, 1992; Barbara et al., 2008). Although widely distributed throughout the body, key areas of cholinergic transmission in the honeybee are the antennal lobes and mushroom bodies (thought to be involved in some aspects of olfactory conditioning, e.g. odor discrimination) located in the head (Barbara et al., 2008).

Neonicotinoids have been shown to bind to the ligand gated ion channels (LGIC) at the $\alpha$-bungarotoxin site on $\mathrm{nAChR}$, along with other ligands including acetylcholine (Lind et al., 1999; Liu and Casida, 1993; Matsuo et al., 1998; Nakayama and Sukekawa, 1998; Schmuck et al., 2003; Tomizawa et al., 1995; Tomizawa and Yamamoto, 1992; Tomizawa and Yamamoto, 1993). Although nAChRs are located on both the pre and post-synaptic membrane, neonicotinoids are more likely to affect post synaptic nAChRs (Buckingham et al., 1997). Once bound to the nAChR, neonicotinoids are not broken down by acetyl cholinesterase like acetylcholine. This leads to over-stimulation of the nervous system and a buildup of acetylcholine in the synapse.

Studies have confirmed that neonicotinoids bind to a single binding site in honeybees (Tomizawa et al., 1995). Studies evaluating the effects of neonicotinoids on continued nerve transmission across the synapses have identified different binding properties. Imidacloprid is a partial agonist of the $\mathrm{nAChR}$ that binds to the acetylcholine (ACh) recognition site (Barbara et al., 2008; Barbara et al., 2003; Benzidane et al., 2011; Deglise et al., 2002). Clothianidin was found to be a full agonist in cockroaches (Periplaneta americana) but this has not been confirmed in honeybees (Benzidane et al., 2011). Nitenpyram, despite having a neonicotinoid structure, behaves more like nicotine, and was observed that it binds to both the ACh site and an allosteric site within the nAChR (Tomizawa and Yamamoto, 1993). Other insect species, such as the peach potato aphid (Myzuspersicae) appear to have an allosteric binding interaction between at least two nicotinic binding sites (Lind et al., 1999).

The LGIC are pentameric molecules composed of five identical subunits (homomeric receptors) or different subunits (heteromeric receptors) arranged round a central pore, which is selective to $\mathrm{Na}^{+}, \mathrm{K}^{+}$and $\mathrm{Ca}^{2+}$ cations (Millar and Lansdell, 2012; Thany et al., 2007). Genome studies have identified $11 \mathrm{nAChR}$ subunit genes in the honeybee (Jones et al., 2007; Jones et al., 2006), compared with 10 each in the fruit fly (Drosophila melanogaster) (Jones et al., 2007). Although studies by Le Novere et al. (2002) and Millar (2003) cited in Millar and Lansdell (2012) identified seventeen subunits in vertebrates $(\alpha 1-\alpha 10, \beta 1-\beta 4, \gamma, \delta, \varepsilon)$, only $\alpha$ and $\beta$ subunits have been found in the honeybee (Dupuis et al., 2011). The combination of subunits determines the functional and pharmacological properties of the receptor (Jones et al., 2007); however, it is thought that the $\alpha$ subunits of two adjacent cysteine residues in Loop C are important in ACh binding (Kao et al., (1984) cited in Jones et al., (2007)). There are core nAChR subunits that are conserved between different insect species with over $60 \%$ homology in their amino acid sequences (Jones et al., 2007; Sattelle, 2009). However, the fruit fly, mosquito and 
honeybee have at least one divergent subunit with less than $20 \%$ homology (Sattelle, 2009). The subunits found in the honeybee are $\alpha 1, \alpha 2, \alpha 3, \alpha 4, \alpha 5, \alpha 6, \alpha 8, \alpha 7, \alpha 9, \beta 1, \beta 2$ (Dupuis et al., 2011) out of which $\alpha 5, \alpha 8$ and $\alpha 9$ are yet to be sequenced (Rocher and Marchand-Geneste, 2008). Different combinations of subunits within the LIGC are present in different receptors throughout the body and may explain the susceptibility of some areas of the honeybee compared with others. For example, $\alpha 2, \alpha 8$ and $\beta 1$ subunits were expressed in adult honeybee Kenyon Cells, whereas an additional subunit $\alpha 7$ was found in the antennal lobes (Dupuis et al., 2011).

Through structure activity relationship (SAR) it has been made possible to identify the 3pyridylmethylamine moiety which is being considered essential for providing the insecticidal properties of neonicotinoids (Tomizawa and Yamamoto, 1992; Tomizawa and Yamamoto, 1993; Yamamoto et al., 1995). Furthermore the difference in binding affinity at the nAChR very well explains the differences in toxicity been observed between species (Matsuo et al., 1998; Rocher and Marchand-Geneste, 2008; Tomizawa and Yamamoto, 1993; Yamamoto et al., 1995).

\section{Detoxification Mechanisms Of Honey Bees (A.Mellifera) Resulting In Tolerance Of Dietary Nicotine}

The honey bee A.melliferais is an ecologically and economically important pollinator species worldwide. Recent declines in bee populations have prompted numerous studies on the factors that influence their vitality (Pott et al., 2010; Vanbergen et al., 2013). No single cause has been identified for the sometimes dramatic over wintering losses of honey bees but rather multiple interacting factors, such as pesticides, malnutrition, habitat loss, parasites and pathogens have been suggested as causing chronic sublethal stress (Vanbergenet al., 2013; Vanengelsdrop et al., 2010; Bryden et al., 2013). Of all the stress factors a group of neurotoxic pesticides, the neonicotinoids, has been singled out due to its extensive use in crop protection (Godfray et al., 2014).

These nicotine-like compounds used for the protection of agricultural crops are systemic insecticides and trace residues can be found in nectar and pollen, andexposing bees that forage on these flowers. Most acute and chronic toxicity studies have been performed under laboratory conditions as semi-field, however field studies assessing toxicity are challenging (controlled multifactor experiments at the landscape scale are very hard to conduct) (Godfray et al., 2014; Blacquiere et al., 2012). As a result it is not yet clear how much neonicotinoid-containing nectar and pollen is collected and stored in bee hives (Mullin et al., 2010), or how much can be tolerated on a colony level (Bryden et al., 2013; Godfray et al., 2014). Apart from the acute and chronic toxicity effects, sublethal effects of dietary neonicotinoids have also raised concerns. Neonicotinoids have been demonstrated to cause adverse effect on bee immunity (Di prisco et al., 2013) as well as behavioral traits, such as communication, homing and foraging (Henry et al., 2012).

One of the principal mechanisms used by insects to escape the adverse effects of both natural and synthetic toxins, such as nicotine and the neonicotinoids is through metabolic resistance. The major enzyme super families responsible for the metabolism or detoxification of toxins are the cytochrome P450 monooxygenases (P450s), glutathione transferases (GSTs) and carboxylesterases (COEs) (Li et al., 2007). The sequencing and annotation of the honey bee genome revealed a $50 \%$ or greater reduction in the number of genes encoding for these enzyme families relative to other insect genomes (Claudianos et al., 2006). A comprehensive review on pesticide toxicity data (Hardstone et al., 2010) found that while honey bees can be sensitive to individual insecticides, andthey are no more vulnerable than other insect species. However, it has been suggested that the smaller number of detoxification genes may limit the capacity of honey bees to metabolize multiple toxins simultaneously, which causes bees to be more sensitive to synergistic interactions of pesticides e.g. competitive inhibition of P450s (Johnson et al., 2009; Johnson et al., 2012).

Several studies have demonstrated the involvement of the P450-, GST- or COE-enzyme families in pesticide and secondary metabolite detoxification in honey bees (Johnson et al., 2006, 2009, 2012; Mao et al., 2009, 2011, Feyereisen 2012). Papadopoulos et al. (2004) were the first to assign a function to a specific honey bee cytochrome P450 enzyme by demonstrating that CYP6AS3 is involved in the detoxification of quercetin, a flavonol present in pollen and numerous floral nectars, while CYP9Q1, CYP9Q2 and CYP9Q3 were the first specific P450s identified to contribute to pesticide (tau-fluvalinate and coumaphos) detoxification in honey bees (Mao et al., 2011). However, even though we are able to link specific enzymes or enzyme families to honeybee detoxification processes, the overall protection mechanisms that allow these insects to tolerate the variety of potentially toxic secondary metabolites and pesticides encountered in floral nectars and pollen remain largely unknown.

Nicotine is a highly toxic alkaloid primarily found in the plant family Solanaceae, including tomato, potato, green pepper and tobacco. It is a broadly effective defense against herbivores, with a mode of action resembling that of synthetic neonicotinoids; and is used as a non-syntheticinsecticide in the form of tobacco tea in organic farming methods (Isman et al., 2006). Nicotine mimics acetylcholine at the neuromuscular junction in mammals, causing twitching, convulsions and even death (Steppuhn et al., 2004; Tomizawa et al., 2003). In susceptible insects, the same mode of action is observed in the ganglia of the central nervous system. Only a few 
insect species such as Myzus persicae (susceptible strains LC50<30; resistant strains LC50 >200 ppm), Bemisia tabaci (resistant strains LC50 $=2000$ to $10000 \mathrm{ppm}$ ) and Manduca sexta are known to tolerate nicotine in their diet (Bass et al., 2013; Kliot et al., 2014; Snyder et al., 1995). Honey bees encounter nicotine in the nectar and pollen of Nicotiana species at levels between 0.1 and $5 \mathrm{ppm}$ in nectar and up to $23 \mathrm{ppm}$ in pollen (Tadmor et al., 2004; Detzel et al., 1993; Singaravelan et al., 2006). Studies investigated on the effect of dietary nicotine on the survival of bees showed that not only naturally occurring concentrations of nicotine do not deter honey bees, but also that nectar nicotine at concentrations up to $50 \mathrm{ppm}(300 \mu \mathrm{M})$ had no notable detrimental effects on worker survival, hatching success or larval survival (Singaravelan et al., 2005; Human et al., 2014; Kohler et al., 2012; Singaravelan et al., 2006). In comparison to nicotine-sensitive aphids which showed $100 \%$ mortality after six days on a diet containing $30 \mathrm{ppm}$ nicotine (Bass et al., 2013), honey bees tolerated $50 \mathrm{ppm}$ nicotine in their diet during 21 day survival studies (Kohler et al., 2012) (honey bee LC50 = 2000 ppm) (Detzel, 1993).

In the insect species that have adapted to nicotine-producing plants, such as M. persicae, B. tabaci and M. sexta, nicotine tolerance is linked to cytochrome P450-mediated detoxification (Bass et al., 2013; Kliot et al., 2014; Snyder et al., 1995). It is widely assumed that metabolic detoxification mechanisms in insects are energetically expensive (Guedes et al., 2006; Cress well et al., 1992); however, the absence of evidence for costs has also been reported (Kliot et al., 2014). Previously, we demonstrated that dietary nicotine had no significant adverse effects on lipid and protein reserves in honey bee larvae (Human et al., 2014), suggesting negligible energetic or metabolic costs associated with the observed nicotine tolerance.

To date, studies investigating the mechanisms involved in detoxification of pesticides and secondary metabolites in honey bees have utilized in vitro metabolism assays (enzyme assays) or toxicity bioassays in the presence or absence of known inducers or inhibitors of specific enzyme families involved in detoxification (Johnson et al., 2012, 2006; Mao et al., 2009, 2011, 2013). Systems biology approaches include genome-wide transcriptome analysis of specific tissues such as the midgut or the abdomen (Mao et al., 2013; Schmehl et al., 2014; Aufauvre et al., 2014) or transcriptomic analysis of selected detoxification, immune and stress response genes (Johnson et al., 2012; Mao et al., 2011) after pesticide or xenobiotic exposure. However, mRNA expression profiles do not always correlate with protein concentrations and metabolic state. Therefore, in this study we employed an integrated proteomic and metabolomic approach to attain a global overview of the response of honey bees to a three day nicotine exposure.

Honey bees' genome is characterized by a paucity of genes associated with detoxification, which makes them vulnerable to specific pesticides, especially to combinations of pesticides in real field environments. Many studies have investigated the mechanisms involved in detoxification of xenobiotics/pesticides in honey bees, from primal enzyme assays or toxicity bioassays to characterization of transcript gene expression and protein expression in response to xenobiotics/insecticides by using a global transcriptomic or proteomic approach, and even to functional characterizations. The global transcriptomic and proteomic approach allowed us to learn that detoxification mechanisms in honey bees involve multiple genes and pathways along with changes in energy metabolism and cellular stress response. P450 genes, is highly implicated in the direct detoxification of xenobiotics/insecticides in honey bees and their expression can be regulated by honey/pollen constitutes, resulting in the tolerance of honey bees to other xenobiotics or insecticides. P450s is also a key detoxification enzyme that mediates synergism interaction between acaricides/insecticides and fungicides through inhibition P450 activity by fungicides or competition for detoxification enzymes between acaricides (Gung and Diao, 2016).

\section{Honey Constituents Up-Regulate Detoxification And Immunity Genes In The Western Honey Bee A.Mellifera}

The western honey bee A.mellifera is the most important managed pollinator species in the world; in the United States, its pollination services are estimated at contributing \$14 billion annually to the economy (Calderone et al., 2012). The apicultural industry in the United States, however, has been threatened in recent years by substantial colony losses. During the past 5 years, annual losses have amounted to $\sim 30 \%$ of managed colonies in the United States (Vanengelsdrop et al., 2007, 2008, 2010, and 2012). Colonycollapse disorder, a suite of symptoms associated with many of these losses, is characterized by a sudden disappearance of worker bees (Vanengelsdrop et al., 2007, 2008, 2010, 2012; Oldroyd et al., 2007). Multiple factors have been investigated as potentialcauses of or factors contributing to CCD, including honey bee pathogens and parasites spanning several kingdoms (Cox-Foster et al., 2007; Evans et al., 2011; Cornmans et al., 2012) as well as exposure to pesticides that compromise immune responses (Alaux et al., 2010; Pettis et al., 2012), navigation ability, learning and memory (Henry et al., 2012). As the bees must gather nectar for honey from spring through fall in temperate regions to make sufficient honey to maintain the colony through the winter months, they use a spectacular diversity of plant species as nectar sources. Indeed, their ability to pollinate so many different plant species contributes to their status as the premier managed pollinator in agricultural systems worldwide. However, despite the potential exposure to a broad diversity of phytochemicals in the nectar of the diverse 
flower species visited, the honey bee genome is characterized by a paucity of genes associated with detoxification. Cytochrome P450 monooxygenases (P450s) are among the principal phase I detoxification enzymes used by organisms, including insects, to metabolize xenobiotics, including phytochemicals and insecticides (Mao et al., 2009). Whereas most other insect genomes contain 80 or more cytochrome P450 genes, A.mellifera has only $46 \mathrm{P} 450$ genes (Claudianos et al., 2006). Honey bees metabolize phytochemicals found in honey and pollen as well as acaricidesused in-hive for management of Varroa destructor, an ectoparasitic mite of honey bees, via a number of CYP6 and CYP9 familymembers. Quercetin, a flavonoid constituent of honey and pollen, is metabolized by three enzymes in the CYP6AS subfamily and two enzymes in the CYP9Q subfamily (Mao et al., 2009, 2011), whereas the acaricides coumaphos and $\tau$-fluvalinate are detoxified by three enzymes in the CYP9Q subfamily (Mao et al., 2011). Regulation of these detoxification genes in A.mellifera differs in some respects from P450 regulation in other insects (Li et al., 2007) in that CYP6AS3, which metabolizes quercetin, is not inducible by its substrate or by Phenobarbital, a classic experimental inducer of insect P450 transcription. Regulation of genes involved in detoxification of dietary phytochemicals may be different in bees because honey, the principal source of energy to meet the metabolic needs of the hive, is processed from diverse floral nectar sources and its phytochemical composition varies according to locality and phenology. That P450s are regulated by predictable constituents of host plants in most insect herbivores (Li et al., 2007) suggests that there may be predictable constituents of honey that serve as specific inducers of detoxification enzymes. p-coumaric acid specifically up-regulates all classes of detoxification genes as well as selected antimicrobial peptide genes. This up-regulation has functional significance in that adding p-coumaric acid to a diet of sucrose increases midgut metabolism of coumaphos, a widely used in-hive acaricide, by $\sim 60 \%$. As a major component of pollen grains, p-coumaric acid is ubiquitous in the natural diet of honey bees and may function as a nutraceutical regulating immune and detoxification processes.

\section{Detoxifying Enzymes In Honeybees}

The honeybee genome has substantially fewer protein coding genes than Drosophila melanogaster and Anopheles gambiae with some of the most marked differences occurring in three superfamilies encoding xenobiotic detoxifying enzymes (Claudianos et al., 2006). This variation makes extrapolation of responses to both individual pesticides and pesticide mixtures between species less reliable as there are only about half as many of the three major xenobiotic metabolizing enzymes glutathione-S-transferases (GSTs), cytochrome P450 monooxygenases (P450s) and carboxyl/cholinesterases (CCEs) in the honeybee. The glutathione-S-transferases group of enzymes that catalyze the metabolism of pesticides by conjugation of reduced glutathione, via a sulfhydryl group, to electrophilic centers on a wide variety of substrates. The $\mathrm{P} 450$ s catalyze a range of reactions including oxidation and demethylation which may result in decrease in activity or produce active metabolites, e.g. the conversion of the neonicotinoid thiamethoxam to clothianidin.

The midgut in the honeybee is a major site of metabolism for ingested pesticides and interactions between chemicals at least in part may be influenced by effects on the detoxifying enzymes within the midgut, including microsomal oxidases, glutathione S-transferases and esterases. Microsomal oxidase assay required intact midgut because an inhibitor of P450 is released when midguts are dissected and midgut microsomal preparations contained mainly cytochrome P-420, the inactive form of cytochrome P-450, which may explain the low microsomal oxidase activity in microsomes (Johnson et al., 2009). The microsomal oxidase activities include aldrinepoxidase activity which is inhibited by malathion and permethrin, N-demethylase activity which is induced by diazinon and EPN neonicotinoid and O-demethlase activity which is induced by diazinon. Of the glutathione S-transferases, aryl transferase activity is significantly induced by diazinon and moderately induced by permethrin. Carboxylesterase activity is moderately inhibited by malathion and permethrin (Suh and Shim, 1988). The P450s are thought to play a central role in insects in the metabolism of phytochemicals ( $\mathrm{Li}$ et al., 2007). Examples of such phytochemicals relevant to honeybees are the flavonoids (flavonolese, quercetin, kaempherol, galangin, fisetin, flavanones e.g. pinocembrin, naringin, hesperidin and flavones e.g. apigenin, acacetin, chrysin, luteolin) which occur as glycosides in nectar and are hydrolyzed to aglycones during the formation of honey and are also present in propolis and pollen (Viuda-Martos et al., 2008). However, when compared with other insects there are a significantly lower number of CYP3 clans (which include the CYP6s and CYP9s) associated with xenobiotics metabolism encoded in the honeybee genome (Johnson et al., 2010). Although this may be related to the reduced exposure to chemically-defended plant tissues there is some suggestion that others e.g. the CYP6AS subfamily, have undergone an expansion relative to other insects (Mao et al., 2011). CYP6 enzymes are recognized as being involved in the metabolism of dietary constituents in herbivorous insects ( $\mathrm{Li}$ et al., 2007). Therefore this expansion may be due to the presence of specific phytochemicals in the diet, e.g. in pollen and nectar, which may be concentrated in honey and bee bread (Adler, 2000). The link to phytochemical exposure in honeybees is supported by the upregulation of three of the CYP6AS genes in response to consumption of honey (Johnson, 2008). 
Detailed studies by Suchail et al. (2004a, b) using radiolabelled $\left[\mathrm{C}^{14}\right]$ imidacloprid have identified the distribution and metabolic pathways of imidacloprid in honeybees. Imidacloprid is readily metabolized (possibly by mixed function oxidases (Phase I metabolism)) to more water soluble products with an elimination half-life of $5 \mathrm{~h}$; there is no evidence of conjugation prior to elimination. Six and $24 \mathrm{~h}$ after ingestion of imidacloprid at 20 and $50 \mu \mathrm{g} / \mathrm{kg}^{-1}$ bee, no imidacloprid was detected in the honeybee (Suchail et al., 2004b). There are 5 metabolic products; 6-chloronicotinic acid is formed by the oxidative cleavage of the imidacloprid methylene bridge, urea derivative is formed by the reduction of the nitro group, hydroxylation of the imidazolidine ring to form 4,5dihydroxy-imidacloprid and then 4/5-hydroxy-imidacloprid, and the dehydration of the 4/5-hydroxyimidacloprid and/or desaturation of the imidazolidine moiety of imidacloprid to olefin. The main metabolites are the urea derivative and 6-chloronicotinic acid. Unlike mammals, there was no guanidine derivative detected (Suchail et al., 2004).

Suchail et al. (2004a) also reported the distribution of imidacloprid and its metabolites throughout the body of the honeybee. The rapid appearance of metabolites throughout the body, combined with variations in the kinetic profile suggests that metabolism also occurs outside of the main focus in the midgut. The main metabolites, urea derivative and 6-chloronicotinic acid, were found particularly in the mid gut and rectum. In addition, 4/5-hydroxy-imidacloprid and olefin were found mostly in the head, thorax and abdomen, all of which are $\mathrm{nAChR}$ rich tissues. Furthermore, concentrations of these two metabolites peaked $4 \mathrm{~h}$ after ingestion of 100 $\mu \mathrm{kg}^{-1}$ bee.

The kinetics profiles can be related to the two distinct phases ofimidacloprid poisoning after acute exposure. There is a rapid onset of neurotoxicity in the form of hyper responsiveness, hyperactivity, and trembling; mortality is delayed until at least four hours post exposure (Suchail et al., 2004a, b, 2001). Insecticidal properties were found with olefin, and 4/5-hydroxy-imidacloprid which retain nitroguanidine $\left(\mathrm{CH}_{4} \mathrm{~N}_{4} \mathrm{O}_{2}\right)$. LD50 values show that the olefin ( $48 \mathrm{~h}$ oral LD50 $\left.>36 \mathrm{ng} / \mathrm{bee}\right)$, in particular, is of similar toxicity to imidacloprid (48 h oral LD50 $41 \mathrm{ng} / \mathrm{bee}$ ) to bees (Nauen et al., 2001). Furthermore, both metabolites were found to bind to the $\mathrm{nAChR}$. The delayed onset of death is thought to be as a result of the appearance of these toxic metabolites (Nauen et al., 2001; Schmuck et al., 2003). A similar metabolic fate study was conducted by Brunet et al., (2005) using radiolabelled $\left[\mathrm{C}^{14}\right]$-acetamiprid. Acetamiprid is readily metaboliszed by mixed function of oxidases. Out of seven metabolites been detected, 6-choronicotinic acid (IC 0) and U1 are considered to be important.

Although metabolism is fast, with $50 \%$ of acetamipridmetabolized $30 \mathrm{~min}$ after oral dosing with $100 \mu \mathrm{g}$ $\mathrm{kg}^{-1}$ bee, only $40 \%$ of the total radioactivity was eliminated after $72 \mathrm{~h}$. This suggests that both the metabolites and parent compound persist within the honeybee. However, none of the breakdown products have insecticidal qualities (Iwasa et al., 2004). The low toxicity of acetamiprid to honeybees is believed to be because of this rapid metabolism (half-life $25 \mathrm{~min}$ ). (Brunet et al., 2005) also evaluated the distribution of acetamiprid and its metabolites in different compartments of the honeybee. Acetamiprid was rapidly distributed in all compartments and metabolized. Initially, acetamiprid was mainly detected in nAChR tissues of the abdomen, head and thorax with a distribution profile similar to that of imidacloprid (Suchail et al., 2004a). However unlike imidacloprid, significant levels of metabolites were detected at $72 \mathrm{~h}$ throughout the honeybee compartments.

The metabolism of neonicotinoids was further explored by Iwasa et al. (2004), who used synergists of both Phases I and II enzymes to identify the metabolic pathways used in neonicotinoid detoxification. This study confirmed the multiple functions of oxidases in the metabolism of many neonicotinoids. However, the toxicity of imidacloprid was not increased by the presence of potent cytochrome P450 inhibitors, such as piperonylbutoxide and Ergosterol Biosynthesis Inhibitors (EBI) suggesting P450s have a lesser role.The metabolomic and proteomic analyses show active detoxification of nicotine in bees, associated with increased energetic investment and also antioxidant and heat shock responses. The increased energetic investment is significant in view of the interactions of pesticides with diseases such as Nosema species which cause energetic stress and possible malnutrition (Ester et al., 2015).

\section{Conclusion}

Neonicotinoid pesticides (e.g. imidacloprid, clothianidin and thiamethoxam)are widely used for the systemic protectionof crops against biting and sucking insect pests.However, thecontinuous application of neonicotinoidsincreases the risk of pollinator'sloss due to their high toxicity to the honey bees. The loss of bee populations will cause a significantreduction of the cereal crop yields and consequently threaten the livelihood of human beings. So,it is high time wesavedthe non-targeted honeybees from the toxic chemicals by making different formulations of neonicotinoids which should be active against pest but should be non-toxic to honey bees which are nature's friendly creatures that benefit the ecosystem in a wide range of ways like pollination, provision of man with nutritional honey and bee wax. 


\section{References}

[1]. Aufauvre J, Aucouturier B, Vigues B, Catherine T, Frederic D, Nicolas B (2014). Transcriptome analyses of the honeybee response to Nosema ceranae and insecticides. PLoS ONE 9, e91686.

[2]. Adler LS (2000). The ecological significance of toxic nectar.OIKOS 91: 409-420.

[3]. Alaux C, Lucbrunet J, Dussaubat C, Mondet F, Tchamitchan S, Cousin M, Brillard J, Baldy A, Belzunces LP, Leconte Y (2010). Interactions between Nosema microspores and a neonicotinoid weaken honeybees (Apis mellifera). Environ Microbiology 12(3):774-782.

[4]. Bass C, Zimmer CT, Riveron JM, Wilding CS, Wondji CS, Kaussmann M, Field LM, Williamson MS, Nauen R (2013). Gene amplification and microsatellite polymorphism underlie a recent insect host shift. Proc. Natl. Acad. Sci. 110: 19460-19465.

[5]. Barbara G, Zube C, Rybak J, Gauthier M, Gru“ newald B. (2003) Ionotropic receptors of cultured honey bee antennal lobe neurons. In: Eisner N, Zimmermann H, editors. Proceedings of the $5^{\text {th }}$ meeting of the German neuroscience society. New York' George Thyme Verlag Stuttgart; p. $856-7$

[6]. Barbara GS, Grunewald B, Paute S, Gauthier M, Raymond-Delpech V (2008). Study of nicotinic acetylcholine receptors on cultured antennal lobe neurones from adult honeybee brains. Invert Neurosci. ; 8(1):19-29. doi: 10.1007/s10158-007-0062-2.

[7]. Belzunces LP, Tchamitchian S, Brunet JL (2012).Neural effects of insecticides in the honey bee. Apidologie. 43:348-370.

[8]. Benzidane,Y, Lapied B, Thany SH (2011). "Neonicotinoid insecticides imidacloprid and clothianidin affect differently neural Kenyon cell death in the cockroach Periplaneta americana." Pesticide Biochemistry and Physiology 101(3): 191-197.

[9]. BlacquièreT, Smagghe G, Van Gestel CA M, Mommaerts V (2012). Neonicotinoids in bees: a review on concentrations, sideeffects and risk assessment. Ecotoxicology 21: 973-992.

[10]. Bromilow RH, Chamberlain K, EvansAA (1990).Physicochemical aspects of phloem translocation of herbicides. Weed Science. 38:305-314

[11]. Brunet J L, Badiou A,Belzunces LP (2005)."In vivo metabolic fate of [C-14]-acetamiprid in six biological compartments of the honeybee, Apis mellifera." Pest Management Science 61(8): 742-748.

[12]. Bryden J, Gill RJ, Mitton R A A, Raine N E, Jansen VA A (2013). Chronic sublethal stress causes bee colony failure. Ecol. Letters. 16: 1463-1469.

[13]. Buckingham SD, Lapied B, Le Corronc H, Grolleau F, Sattelle DB (1997). Imidacloprid actions on insect neuronal acetylcholine receptors. J ExpBiol 1997.200:2685-2692.

[14]. Calderone NW (2012). Insect pollinated crops, insect pollinators and US agriculture: Trend analysis of aggregate data for the period 1992-2009. PLoS ONE 7(5):e37235, 10.1371/journal. pone. 0037235.

[15]. Casida JE, Liu M.Y (1993). High Affinity Binding of [ $\left.{ }^{3} \mathrm{H}\right]$ Imidacloprid in the Insect Acetylcholine Receptor. Pesticide Biochemistry and Physiology. Volume 46, Issue 1, Pages 40-46.

[16]. Casida JE (2010). Neonicotinoid metabolism: compounds, substituent's, pathways, enzymes, organisms, and relevance. Journal of Agriculture and Food Chemistry.59:2923-2931.

[17]. Casida JE, Durkin K (2013). Neuroactive insecticides: targets, selectivity, resistance, and secondary effects. Annual Review of Entomology. 58:99-117.

[18]. Cutler P, Slater R, Edmunds JF, Maienfisch P, Hall RG, Earley GP, Pitterna T, Pal S, Paul V-L, Goodchild J, Blacker M, HagmannL,CrossthwaiteAJ (2013). Investigating the mode of action of sulfoxaflor: a fourth-generation neonicotinoid.Pest Management Science. 69:607-619.

[19]. Cox-Foster DL, Colan S, Holmes EC, Palacios G, Evans JD, Moran NA, Quan PL, Briese T, Hornig M, Geiser DM, Martinson VengElsdorp DV, Kalkstein AL, Drysdale A, Hui J, Zhai J, Cui L, Hutchison

[20]. SK, Simons JF, Egholm M, Pettis JS, Lipkin WI (2007).A Metagenomic survey of microbes in honey bee colony collapse disorder.Science. 318(5848):283-287.

[21]. Cornman RS, Tarpy DR, Chen Y, Jeffreys L, Lopez D, Pettis JS, VanEngelsdorp D, Evans JD (2012). Pathogen webs in collapsing honey bee colonies. PLoS ONE 7(8):e43562, 10.1371/journal.pone.0043562.

[22]. Claudianos C, Ranson H, Johnson RM, Biswas S, Schuler MA, Berenbaum, Feyereisen R, Oakeshott JG (2006). A deficit of detoxification enzymes: pesticide sensitivity and environmental response in the honeybee. Insect Mol. Biol. 15: 615-636.

[23]. Cresswell J E, Merritt S Z, Martin M M (1992). The effect of dietary nicotine on the allocation of assimilated food to energy metabolism and growth in fourth-instar larvae of the southern army worm, Spodoptera eridania (Lepidoptera: Noctuidae). Oecologia 89: 449-453.

[24]. Castañeda L E, Figueroa CC, Fuentes-Contreras E, Niemeyer H M, Nespolo RF (2009). Energetic costs of detoxification systems in herbivores feeding on chemically defended host plants: a correlational study in the grain aphid, Sitobionavenae. J. Exp. Biol. 212: 1185-1190.

[25]. Deglise P, Grunewald B (2002). "The insecticide imidacloprid is a partial agonist of the nicotinic receptor of honeybee Kenyon cells." Neuroscience Letters.321(1-2): 13-16

[26]. Detzel, A. \& Wink, M. (1993).Attraction, deterrence or intoxication of bees (Apis mellifera) by plant allelochemicals.Chemoecology. 4: 8-18.

[27]. Di PriscoG, Cavaliere V, Annoscia D, Varricchio P, Caprio E, Nazzi F, Gargiulo G, Pennacchio F. et al. (2013). Neonicotinoidclothianidinadversely affects insect immunity and promotes replication of a viral pathogen in honey bees. Proc. Natl. Acad. Sci. 110: 18466-18471.

[28]. Dupuis J.P, Gauthier M, Raymond-Delpech V. (2011) Expression patterns of nicotinic subunits alpha 2, alpha 7, alpha 8, and beta affect the kinetics and pharmacology of ACh-induced currents in adult bee olfactory neuropiles. J. Neurophysiol. 106, $1604-1613$.

[29]. Esther E, Smith S, Beukes M, Apostolides Z, Prirk CWW, Nicolson SW (2015). Detoxification mechanisms of honey bees (Apis mellifera) resulting in tolerance of dietary nicotine. Nature. 11779

[30]. Evans JD, Schwarz RS (2011). Bees brought to their knees: Microbes affecting honeybee health. Trends Microbiology. 19(12):614620.

[31]. European Food Safety Authority (2012) statement on the findings in recent studies investigating sub-lethal effects in bees of some neonicotinoids in consideration of the uses currently authorized in Europe. EFSA J 10:2752

[32]. Feyereisen R (2012).Insect CYP genes and P450 enzymes. Insect Molecular Biology andBiochemistry, ed Gilbert LI (Elsevier/Academic Press, Amsterdam) pp 236-316.

[33]. Godfray H C J, Charles H, Blacquiere T, Linda MF, Rosemary SH, Gillian P, Simon GP, Nigel E R, Adam JV, Angela RM (2014).A restatement of the natural science evidence base concerning neonicotinoid insecticides and insect pollinators.Proc. R. Soc. B Biol. Sci. 281: 20140558. 
[34]. Guedes R N C, Oliveira E E, Guedes N M P, Ribeiro B, Serrao J E (2006). Cost and mitigation of insecticide resistance in the maize weevil, Sitophilus zeamais. Physiological Entomology. 31: 30-38.

[35]. Gung Y, Diao Q (2016). Current knowledge of detoxification mechanisms of xenobiotic in honey bees. Ecotoxicology doi:10.1007/s10646-016-1742-7.

[36]. Henry M, Beguin M, Requier F, Rollin O, Odoux JF, Aupinel P, Aptel J, Tchamitchian S, Dcourtye A (2012). A common pesticide decreases foraging success and survival in honey bees. Science 336: 348-350.

[37]. Hardstone M C, Scott J G (2010). Is Apis mellifera more sensitive to insecticides than other insects Pest Management Sci. 66: 11711180 .

[38]. Heather P (2012). Pesticides and Honey Bees: state of the sciences. Pan North America.Human H, Archer C R, Du R, E. E, Pirk C W W, Nicolson SW (2014).Resistance of developing honeybee larvae during chronic exposure to dietary nicotine. J. Insect Physiol. 69: 74-79.

[39]. Isman MB (2006). Botanical insecticides, deterrents, and repellents in modern agriculture and an increasingly regulated world.Annual Review of Entomology. 51: 45-66.

[40]. Iwasa T, Motoyama N, Ambrose JT, Roe RM (2004)."Mechanism for the differential toxicity of neonicotinoid insecticides in the honey bee, Apis mellifera." Crop Protection 23(5): 371-378.

[41]. Johnson RM, Wen Z, Schuler M A, Berenbaum (2006). M. R. Mediation of pyrethroid insecticide toxicity to honey bees (Hymenoptera:Apidae) by cytochrome P450 monooxygenases. Journal of Economic Entomology.99: 1046-1050.Johnson RM (2008). Toxicogenomics of Apis mellifera, Graduate College of the University of Illinois at Urbana-Champaign.

[42]. Johnson RM, Pollock HS, Berenbaum MR (2009). Synergistic interactions between in-hive miticides in Apis mellifera. Journal of Economic Entomology 102:474-479.

[43]. Johnson RM, Ellis MD, Mullin CA, and Frazier M (2010). Pesticides and honey bee toxicity - USA. Apidologie 41 .312-331.

[44]. Johnson, RM, Mao W, Pollock HS, Niu G, Schuler MA, Berenbaum MR (2012). Ecologically appropriate xenobiotics induce cytochrome P450s in Apis mellifera. PLoS ONE 7, e31051

[45]. Jones A K, Raymond-Delpech V, Thany SH, Gauthier M, Sattelle DB (2006). "The nicotinic acetylcholine receptor gene family of the honey bee, Apis mellifera." Genome Research 16(11): 1422-1430.

[46]. Jones A K, BrownLA,Sattelle DB (2007). "Insect nicotinic acetylcholine receptor gene families: from genetic model organism to vector, pest and beneficial species." Invertebrate Neuroscience 7(1): 67-73.

[47]. Kao, L, Motoyama, N and Dauterman, W (1984) Studies on hydrolases in various house fly strains and their role in malathion resistance. Pesticide Biochemistry and Physiology 22: 86-92.

[48]. Kliot A, Kontsedalov S, Ramsey JS, Jander G, Ghanim M (2014). Adaptation to nicotine in the facultative tobacco-feeding hemipteran Bemisia tabaci Pest Management Science.70:1595-1603.

[49]. Köhler A, Pirk, C. W. W. \& Nicolson, S.W (2012). Honeybees and nectar nicotine: Deterrence and reduced survival versus potential health benefits. J. Insect Physiol. 58, 286-292.

[50]. Le Novere N, Corringer PJ, Changeux JP (2002) The diversity of subunit composition in nAChRs: evolutionary origins, physiologic and pharmacologic consequences. J Neurobiol 53:447-456.

[51]. Li X, Schuler MA, Berenbaum MR (2007) Molecular mechanisms of metabolic resistance to synthetic and natural xenobiotics. Annu Rev Entomol 52:231-253.

[52]. Liu Z, Yao X, Zhang Y (2008). Insect nicotinic acetylcholine receptors (nAChRs): important amino acid residues contributing to neonicotinoid insecticides selectivity and resistance. Afr J Biotechnol.7:4935-4939.

[53]. Liu GY, Ju XL, Cheng J (2010). Selectivity of Imidacloprid for fruit fly versus rat nicotinic acetylcholine receptors by molecular modeling. JMol Model. 16:993-1002.

[54]. Lind R J, Clough MS, Reynolds SE, Earley FGP (1999). "Characterization of multiple alpha-bungaro toxin binding sites in the aphid Myzuspersicae (Hemiptera:Aphididae)." Insect Biochemistry and Molecular Biology 29(11): 979-988.

[55]. Matsuda K, Buckingham SD, Kleier D, Rauh JJ, Sattelle DB (2001). Neonicotinoids: insecticides acting on insect nicotinic acetylcholine receptors. Trends in Pharmacological Science .22:573-580.

[56]. Matsuda K, Shimomura M, Ihara M, Akamatsu M, Sattelle DB (2005). Neonicotinoids show selective and diverse actions on their nicotinic receptor targets: electrophysiology, molecular biology, and receptor modeling studies. Biosci Biotechnol Biochem 69:1442-1452.

[57]. Mao W, Rupasinghe SG, Johnson RM, Zangerl AR, Schuler MA, Berenbaum MR et al. (2009) Quercetin-metabolizing CYP6AS enzymes of the pollinator Apis mellifera (Hymenoptera: Apidae). Comp Biochem. Physiol B Biochem.MolBiol 154(4):427-434.

[58]. Mao W, Schuler MA, and Berenbaum MR (2011). CYP9Q-mediated detoxification of acaricides in the honey bee Apis mellifera. Proceedings of the National Academy of Sciences of the United States of America 108 .12657-12662.

[59]. Mao W, Schuler MA, Berenbaum MR (2013). Honey constituents up-regulate detoxification and immunity genes in the western honey bee Apis mellifera. Proc. Natl. Acad. Sci. 110: 8842-8846.

[60]. Millar, N. S. and S. J. Lansdell (2012).Characterisation of insect nicotinic acetylcholine receptors by heterlolgus expression.Insect Nicotinic Acetylcholine Receptors. S. H. Thany. Heidelberger Platz 3, D-14197 Berlin, Germany, Springer-Verlag Berlin. 683: 6573.

[61]. Matsuo H, Tomizawa M, Lzuru Y (1998). "Structure-activity relationships of acyclic nicotinoids and neonicotinoids for insect nicotinic acetylcholine receptor/ion channel complex." Archives of Insect Biochemistry and Physiology 37(1): 17-23.

[62]. Mullin CA, Frazier M, Frazier JL, Ashcraft S, Simonds R, VanEngelsdorp D (2010). High levels of miticides and agrochemicals in North American apiaries: Implications for honey bee health. PLoS ONE 5, e9754.

[63]. Nakayama A, Sukekawa M (1998)."Quantitative correlation between molecular similarity and receptor-binding activity of neonicotinoid insecticides." Pesticide Science 52(2): 104-110.

[64]. Nauen R, Ebbinghaus-Kintscher U, Schmuck R (2001). Toxicity and nicotinic acetylcholine receptor interaction of imidacloprid and its metabolites in Apis mellifera (Hymenoptera:Apidae). Pest Management Science 57(7): 577-586.

[65]. Oldroyd BP (2007) What's killing American honey bees PLoSBiol 5(6):e168, 10.1371/journal.pbio.0050168.

[66]. Palmer MJ, Moffat C, Saranzewa N, Harvey J, Wright GA, Connolly CN (2013) Cholinergic pesticides cause mushroom body neuronal inactivation in honeybees. Nature Communications. 4:1634.

[67]. Pettis JS, VanEngelsdorp D, Johnson J, Dively G (2012) Pesticide exposure in honeybees results in increased levels of the gut pathogen Nosema. Die Naturwissenschaften99(2):153-158.

[68]. Papadopoulos AI, Polemitou I, Laifi P, Yiangou A, Tananaki C (2004). Glutathione S-transferase in the insect Apis mellifera macedonica. Comparative Biochemistry and Physiology. Part C Toxicol.Pharmacol.139, 93-97. 
[69]. Potts SG, Biesmeijer JC, Kremen C, Neumann P, Schweiger O, Kunin WE (2010). Global pollinator declines: trends, impacts and drivers. Trends in Ecology Evolution. 25. 345-353.

[70]. Pollak P: Fine Chemicals (2011). The Industry and the Business.John Wiley \& Sons.

[71]. Rocher A, Marchand-Geneste N (2008). Homology modelling of the Apis mellifera nicotinic acetylcholine receptor (nAChR) and docking of imidacloprid and fipronil insecticides and their metabolites. Environ Res. 2008 Apr-Jun;19(3-4):245-61.

[72]. Shao X, Liu Z, Xu X, Li Z, Qian X (2013). Overall status of neonicotinoid insecticides in China: production, application and innovation. Journal of Pest Science 38: 1-9.

[73]. Suh YT, Shim JH (1988). Enzyme activities of a honeybee Apis mellifera 1. associated with the degradation of some insecticides. Agricultural Chemistry \& Biotechnology 31: 241-248.

[74]. Suchail SD, Guez (2000)."Characteristics of imidacloprid toxicity in two Apis mellifera subspecies." Environmental Toxicology and Chemistry 19(7): 1901-1905.

[75]. Suchail S, GuezD, Belzunces LP (2001). Discrepancy between acute and chronic toxicity induced by imidacloprid and its metabolites in Apis mellifera. Environmental Toxicology and Chemistry. 20:2482-2486.

[76]. Suchail S, GDe Sousa, Rahmani R, Belzunces LP (2004)."In vivo distribution and metabolisation of 14C-imidacloprid in different compartments of Apis mellifera." Pest Management Science 60 (11): 1056-1062.

[77]. Suchail S, Debrauwer L, Belzunces LP (2004). Metabolism of imidacloprid in Apis mellifera. pp. $291-296$.

[78]. Schmuck R, Nauen R, Ebbinghaus-Kintscher U (2003). Effects of imidacloprid and common plant metabolites of imidacloprid in the honeybee, toxicological and biochemical considerations. Bulletin of Insectology 56 (1) 27-34.

[79]. Sattelle, DB. (2009)."Invertebrate nicotinic acetylcholine receptors-targets for chemicals and drugs important in agriculture, veterinary medicine and human health". Journal of Pesticide Science 34(4): 233-240.

[80]. Singaravelan N, Neeman G, Inbar M, Izhaki I (2005). Feeding responses of free-flying honeybees to secondary compounds mimicking floral nectars.Journal of ChemicalEcology. 31: 2791-2804.

[81]. Singaravelan N, Inbar M, Neeman G, Distl M, Wink M, Izhaki I (2006). The effects of nectar-nicotine on colony fitness of caged honeybees.Journal of Chemical Ecology. 32, 49-59.

[82]. Steppuhn A, Gase K, Krock B, Halitschke R, Baldwin I T (2004). Nicotine's defensive function in nature.PLoS Biol. 2, e217.

[83]. Snyder M J, Walding J K, Feyereisen R (1994).Metabolic fate of the allelochemical nicotine in the tobacco hornworm Manduca sexta.Insect Biochem.Mol. Biol. 24, 837-846.

[84]. Snyder MJ, Stevens J L, Andersen JF, Feyereisen R (1995). Expression of cytochrome genes of the CYP4 family in midgut and fat body of the tobacco hornworm, Manduca sexta. Arch. Biochem. Biophys.321, 13-20.

[85]. Schmehl DR, Teal PEA, Frazier JL, GrozingerCM (2014). Genomic analysis of the interaction between pesticide exposure and nutrition in honey bees Apis mellifera. J.Insect Physiol. 71, 177-190.

[86]. Thany SHG, Lenaers, (2007)."Exploring the pharmacological properties of insect nicotinic acetylcholine receptors." Trends in Pharmacological Sciences 28(1): 14-22.

[87]. Thany, S.H. (2010) Neonicotinoid Insecticides. Historical evaluation and resistance mechanisms. Advances. In: Exp. Med. Biol. $683,75-83$

[88]. Tomizawa M, Yamamoto I (1992)."Binding of nicotinoids and the related compounds to the insect nicotinic acetylcholine receptor." Journal of Pesticide Science 17(4): 231-236.

[89]. Tomizawa M, Yamamoto I. (1993). "Structure activity relationships of Neonicotinoids and imidacloprid analogs". Journal of Pesticide Science 18(1): 91-98.

[90]. Tomizawa, M.; Otsuka, H.; Miyamoto, T.; Eldefrawi, M. E.; Yamamoto, I.(1995)."Pharmacological characteristics of insect nicotinic acetylcholine receptor with its ion channel and the comparison if the effect of nicotinoids and neonicotinoids." Journal of Pesticide Science 20(1): 57-64.

[91]. Tomizawa M, Casida JE (2003). Selective toxicity of neonicotinoids attributed to specificity of insect and mammalian nicotinic receptors. Annu. Rev. Entomol. 48, 339-364.

[92]. Tomizawa M, Casida JE (2005). Neonicotinoid insecticide toxicology: mechanism of selective action. Annu Rev PharmacolToxicol2005, 45:247-268.

[93]. Tomizawa M, Casida JE: (2011). Neonicotinoid insecticides: highlights of a symposium on strategic molecular designs. J Agric Food Chem. 59:2883-2886.

[94]. Tomizawa M (2013). Chemical biology of the nicotinic insecticide receptor. Adv Insect Physiol 44:63-99.

[95]. Tadmor-Melamed H, Markan S, Arieli A, Distil M, Izhaki I (2004). Limited ability of Palestine sunbirds Nectariniaosea to cope with pyridine alkaloids in nectar of tree tobacco Nicotiana glauca.Funct.Ecol. 18: 844-850.

[96]. Vanbergen AJ (2013). The Insect Pollinators Initiative. Threats to an ecosystem service: pressures on pollinators. Front. Ecol. Environ. 11, 251-259.

[97]. VanEngelsdorp D, Underwood R, Caron D, Hayes J, Jr. (2007). An estimate of managed colony losses in the winter of 2006 - 2007: A report commissioned by the Apiary Inspectors of America. Am Bee J 147:599-603.

[98]. VanEngelsdorp D, Hayes J Jr, Underwood RM, Pettis J (2008) A survey of honey bee colony losses in the U.S., fall 2007 to spring 2008. PLoS ONE 3(12):e4071, 10.1371/journal. Pone.0004071.

[99]. VanEngelsdorp D, Hayes J, Jr., Underwood RM, Pettis JS (2010) A survey of honey bee colony losses in the United States, fall 2008 to spring 2009. J Apic Res 49:7-14.

[100]. VanEngelsdorp D, Meixner MD (2010). A historical review of managed honey bee populations in Europe and the United States and the factors that may affect them.J. Invertebr. Pathol.103, S80-S95.

[101]. VanEngelsdorp D, Caron D, Hayes J, Underwood R, Henson M, Rennich K, Spleen A, Andree M, Snyder R (2012). A national survey of managed honey bee 2010-11.

[102]. Viuda-Martos M, Ruis-Navajas Y, Fernandez-L'Opez J, and Perez-'Alvarez JA (2008).Functional Properties of Honey, Propolis, and Royal Jelly.Journal of Food Science 73.R117-R124.

[103]. Winter colony losses in the USA: Results from the Bee Informed Partnership. J Apic Res.51:115-124.

[104]. Yamamoto I, Yabuta G, Tomizawa M, Saito T, Miyamoto T, Kagabu S (1995). Molecular mechanism for selective toxicity of nicotinoids and neonicotinoids. Journal of Pesticide Science 20: 33-40. 